\title{
IGUALDAD, DISCRIMINACIÓN Y TOLERANCIA EN MÉXICO
}

\section{EQUALITY, DISCRIMINATION AND TOLERANCE IN MEXICO}

\author{
José Luis SOBERANES FERNÁNDEZ
}

RESUMEN: En el presente artículo se aborda la no discriminación, la igualdad y la tolerancia como derechos humanos presentes en determinados grupos vulnerables, a saber: las mujeres, los indígenas, las personas con orientación sexual distinta a la heterosexual, adultos mayores, portadores de VIH, niños, discapacitados y minorías religiosas. Las medidas y programas que se han implementado por las instituciones públicas a fin de proteger los derechos de estos grupos vulnerables también son motivo de reflexión. Finalmente el autor llama la atención sobre la discriminación producida por las medidas adoptadas por varios países relativas al virus de la influenza humana AH1N1.

Palabras clave: igualdad, no discriminación, tolerancia y grupos vulnerables.
ABSTRACT: This article approaches the no discrimination, equality and tolerance as human rights present in certain vulnerable groups, as are: women, natives, people with sexual orientation different from heterosexual, elder people, carriers of HIV, children, disabled, religious minorities, among others. The measures and programs that have been implemented by the public institutions created for that purpose are also motive of reflection. Finally, the author draws attention around the discrimination produced by the measures adopted by several countries regarding the virus of human influenza AH1N1.

Descriptors: Equality, Nondiscrimination, Vulnerable Groups and Tolerance. 


\section{INTRODUCCIÓN}

La mañana del viernes 24 de abril del año pasado, 2009, México anunció oficialmente una noticia estremecedora: 20 personas habían muerto durante las tres semanas precedentes (El Universal, 24 de abril de 2009). ¿La causa? Un atípico caso de influenza cuya cepa era de origen porcino. Bastaron unos cuantos minutos para que el mundo entero se enterara de la existencia de un nuevo enemigo de la humanidad: la influenza porcina. Con el anuncio, las reacciones ante la amenaza epidemiológica no se hicieron esperar: de inmediato, en la ciudad de México se suspendieron las actividades escolares, culturales y recreativas, se exhortó a la población a no asistir a lugares concurridos y se recomendó el uso de cubrebocas. El fin de semana inmediato, la Organización Mundial de la Salud advirtió que "estábamos ante una potencial pandemia, una situación muy grave cuya evolución era impredecible". Aquellas declaraciones despertaron la incertidumbre, el miedo, la alarma, la zozobra y el temor al contagio, no sólo entre los nacionales de este país, sino también entre toda la comunidad internacional. Estaba confirmado. Un extraño virus había aparecido. En 48 horas México se había convertido en la fuente del mal; todo aquello que proviniera de su territorio fue considerado bajo sospecha.

¿Por qué me refiero a estos acontecimientos? Los temas de este modesto trabajo son igualdad, discriminación y tolerancia. Podría haber comenzado con enunciar algunas ideas conceptuales sobre estas instituciones; sin embargo, preferí llamar la atención del amable lector de lo ocurrido en México hace poco, pues se trató de un caso límite al que podríamos acudir para analizar las reacciones internacionales que, sobre estas materias, fueron adoptadas hacia México y sus nacionales. Para elaborar este pequeño examen — del cual el lector sacará sus propias conclusiones - es pertinente aclarar lo siguiente. Casi una semana después de que se reportara oficialmente la aparición de la influenza AH1N1, la Organización Mundial de la Salud elevó la alerta sanitaria a la fase 5, esto es, determinó:

1. Que el virus se transmitía de persona a persona;

2. Que se había comprobado su contagio sostenido en por lo menos dos países, y

3. Que el riesgo de una pandemia era inminente. 
En ningún momento dicha organización solicitó el cierre de las fronteras a los países que reportaban casos de infección. Hecho el anuncio, inmediatamente, los países adoptaron sus respectivas medidas de protección. Argentina, Cuba, Ecuador y Perú suspendieron los vuelos desde y hacia México; Francia propuso — sin éxito- a la Unión Europea tomar una medida similar; Israel solicitó — sin dar razones para ello - denominar la enfermedad como "gripe mexicana"; Japón suspendió sus importaciones de carne de puerco de América; Haití rechazó toneladas de ayuda humanitaria provenientes de este país por temor al contagio. La reacción más radical, no obstante, fue la adoptada por China. Además de suspender los vuelos entre ambas naciones, su gobierno determinó el indebido confinamiento de 71 compatriotas por el solo hecho de portar un pasaporte mexicano, pues ninguno de ellos presentó síntomas de influenza. México tuvo que enviar un avión al gigante asiático para repatriar a sus nacionales.

Anunciadas las medidas, algunas voces acusaron a los países de la comunidad internacional de iniciar una ola de discriminación hacia México y sus nacionales. Dados estos hechos, yo pregunto ¿México estaba frente a un caso de políticas discriminatorias? Primero habría que definir qué entendemos por discriminación.

\section{DISCRIMINACIÓN EN MÉXICO}

La discriminación es toda aquella distinción, sin causa racionalmente justificable, que causa un daño o perjuicio a una persona en la esfera de su dignidad. ${ }^{1}$ Usualmente, las distinciones se basan en ciertas situaciones que las personas no pueden o no quieren cambiar, como podrían ser: origen étnico o nacional, género, edad, discapacidad, religión, condiciones de salud, opiniones, condición social o económica, estado civil, preferencias sexuales, así como cualquier otra que atente contra la dignidad humana. Se trata, pues, de un listado abierto, con posibilidad de ampliarse para incluir cualquier distinción cuyo efecto dé como resultado la humillación del individuo. De esta forma, el derecho a la no discriminación está integrado por tres elementos: a) un trato desigual, b) un efecto

1 Véase Rodríguez Cepeda, Jesús, El concepto de la discriminación, México, Consejo Nacional para Prevenir la Discriminación, 2005. 
negativo directo, y c) la ausencia de una razón aceptable que sustente la distinción, de tal forma que se produce una desigualdad no justificada. ${ }^{2}$

Dados estos elementos, volvamos a las medidas adoptadas hacia México por algunos países de la comunidad internacional:

1. Constituían un trato desigual;

2. ¿Crearon un efecto negativo directo en los mexicanos?

3. ¿Eran lo suficientemente razonables para justificar su distinción frente a los nacionales de otros países?

Por ahora, basta señalar simplemente que el derecho a la discriminación es, por sí mismo, un derecho controvertido.

No obstante lo anterior me gustaría formular las siguientes reflexiones. Al examinar políticas públicas o leyes presuntamente discriminatorias no debe perderse de vista los elementos objetivos de cada caso en cuestión. Por ejemplo, resulta recomendable centrar la atención en evaluar si las diferencias impuestas por esas políticas o leyes son lo suficientemente relevantes y justifican un tratamiento diferenciado entre los individuos. ${ }^{3}$ Las distinciones basadas en la raza, el género, la religión o la discapacidad, por ejemplo, no podrían considerarse "relevantes" o "justificativas" de un trato diferenciado. Así pues, podría sostenerse que una política pública o ley es discriminatoria cuando establece distinciones que degradan la dignidad humana, ya sea porque:

1. Aplican estereotipos asociados a las características personales de un individuo o a su pertenencia a un determinado grupo o

2. Porque las distinciones logran el efecto de perpetuar la visión de que una persona es de capacidad inferior o de menor valor como ser humano. ${ }^{4}$

2 Véase Huerta Ochoa, Carla, "La estructura jurídica del derecho a la no discriminación”, en Torre Martínez, Carlos de la (coord.), Derecho a la no discriminación, México, UNAM, Instituto de Investigaciones Jurídicas, 2006, p. 156.

3 Véase Monahan, Patrick, Constitutional Law, 3a. ed., Toronto, Irwin Law, 2006, pp. $428-430$.

4 Este criterio fue sostenido por la Suprema Corte de Justicia de Canadá en el caso Law vs. Canada. Vid. Law vs. Canada (Minister of Employment and Inmigration) [1999] 1 S.C.R. 497. 
En la actualidad, la mayoría de las democracias occidentales han incorporado en sus Constituciones el derecho a la no discriminación, el cual, sobra decir, ha sido reconocido en diversos tratados y convenciones internacionales. ${ }^{5}$ En México dicho derecho tuvo una recepción tardía en nuestro orden jurídico, pues fue hasta 2001 cuando se incorporó en el párrafo tercero, artículo 1o. de la Constitución mexicana. ${ }^{6}$ Esta omisión de reconocimiento no se sustentaba en la ausencia de un fenómeno discriminatorio en el país, sino en la falaz convicción de que los mexicanos éramos un pueblo homogéneo, perfectamente integrado, donde no existían las diferencias. Tuvieron que transcurrir varias décadas e incluso la irrupción de un movimiento $\operatorname{armado}^{7}$ para que México reconociera no sólo su composición multicultural, sino también el hecho de que la inequidad en la distribución de la riqueza, la desigualdad de oportunidades, el subdesarrollo y el machismo habían gestado prácticas discriminatorias de fuerte arraigo, especialmente hacia los grupos más vulnerables de nuestra sociedad: indígenas, mujeres, personas con orientación sexual distinta a la heterosexual, portadores de VIH, niños, adultos mayores, discapacitados, minorías religiosas, entre otras. ${ }^{8}$

No obstante lo anterior, México ha dado importantes avances en estas materias. A partir de la incorporación del derecho a la no discriminación a la Constitución mexicana, la Comisión Nacional de los Derechos Humanos $(\mathrm{CNDH})$ conoce de quejas por presuntos hechos discriminatorios cometidos por autoridades federales. Adicionalmente, el 12 de junio de 2003 entró en vigor la Ley Federal para Prevenir y Eliminar la Discriminación, la cual, como su nombre lo indica, fue expedida para combatir el fenómeno discriminatorio y promover la igualdad de oportunidades y

5 Entre ellos se pueden mencionar la Convención Internacional sobre la Eliminación de Todas las Formas de Discriminación Racial; la Convención Internacional sobre la Represión y el Castigo del Crimen del Apartheid; Convención de los Derechos del Niño; la Convención sobre los Derechos de las Personas con Discapacidad y la Convención Interamericana para la Eliminación de todas las Formas de Discriminación contra las Personas con Discapacidad.

6 La reforma constitucional se publicó en el Diario Oficial de la Federación el 14 de agosto de ese año.

7 El Ejército Zapatista de Liberación Nacional se levantó en armas el 1o. de enero de 1994, ocupó la ciudad de San Cristóbal de las Casas, Chiapas, y otras siete cabeceras municipales de ese mismo estado.

8 Torre Martínez, Carlos de la, op. cit., nota 2, p. X. 
trato en México. Aunque su ámbito especial de aplicación únicamente corresponde a la competencia federal, esta Ley dio un paso importante, pues otorgó a la Comisión Nacional para Prevenir la Discriminación la facultad para conocer de quejas motivadas por actos discriminatorios cometidos no sólo por servidores públicos sino también por particulares. Estas últimas quejas, debo aclarar, no son del conocimiento de la CNDH sino del mencionado Consejo Nacional para Prevenir la Discriminación (Conapred), el cual es un órgano nuevo que, por mandato legal, también es responsable de llevar a cabo acciones y políticas públicas encaminadas a prevenir y eliminar la discriminación. De esta forma, actualmente, en el territorio nacional existen diferentes mecanismos de protección del individuo contra la discriminación: a) quejas ante la CNDH y las comisiones públicas estatales de derechos humanos para impugnar actos presuntamente discriminatorios cometidos por servidores públicos; b) quejas ante el Conapred para combatir esos mismos actos cometidos tanto por servidores públicos federales como por particulares, y c) el juicio de amparo, promovido ante el Poder Judicial de la Federación para impugnar la constitucionalidad de leyes discriminatorias. Si bien se trata de tres procedimientos completamente diferenciados, con alcances jurídicos distintos y que podrían empalmarse el uno con el otro, representan tres opciones de entre las cuales el afectado podrá elegir el remedio que le resulte más favorable. ${ }^{9}$

\section{IGUALDAD ENTRE HOMBRES Y MUJERES}

La disparidad entre géneros representa todavía un grave problema social. De acuerdo con el Reporte Global de Brecha de Género 2008, elaborado por el Foro Económico Mundial, México ocupó el lugar 87 de entre 130 países analizados en la muestra, posición que lo ubicó úni-

9 Así, si una persona sufrió un acto de discriminación, podría impugnar la constitucionalidad de la ley en cuestión ante el Poder Judicial de la Federación; si lo que busca es un cambio en las políticas gubernamentales, podrá presentar una queja ante la CNDH para lograr una recomendación; y si su objetivo es cambiar la forma como se conducen los servidores públicos federales o los particulares, podrá acudir al Conapred, donde el referido Consejo determinará la medida más adecuada para evitar que esas conductas se presenten en el futuro. 
camente por encima de Paraguay y Guatemala en América Latina. ${ }^{10} \mathrm{La}$ desigualdad entre hombres y mujeres abarca prácticamente la totalidad de los ámbitos de la vida civil, por lo que aún se observan negativas diferencias en relación con los sexos en la educación, el trabajo, la salud la participación política y la migración. En esta última, por ejemplo, se registró un incremento importante en el porcentaje de mujeres migrantes, quienes actualmente ocupan el $44.4 \%$ de este grupo vulnerable y los hombres, el $55.6 \%$ restante.

En materia laboral, la participación de la mujer en el mundo del trabajo remunerado sigue siendo escasa. Cifras de 2008 demostraron que, mientras la tasa de participación de los hombres en el trabajo extradoméstico fue del 78\%, las mujeres representaron únicamente el 42\%. Estas diferencias se acentuaron en los estados del sur del país como Oaxaca, Chiapas y Tabasco. ${ }^{11}$ Dichos porcentajes revelaron, no obstante, un alto índice de ocupación de las mujeres en las profesiones "feminizadas", como las de comerciantes, vendedoras y dependientas, sin obviar otras de amplia trayectoria femenina como son las trabajadoras domésticas (88.9\%), las vendedoras ambulantes $(62.3 \%)$ y las relacionadas con el magisterio, esta última percibida como la profesión con formación especializada más recurrente en las mujeres. ${ }^{12}$ En contraste, la participación femenina en las profesiones "masculinizadas" — como son la operación de maquinaria agropecuaria y las de protección y vigilancia - es prácticamente inexistente, pues los hombres ocupan el 99.6 y $91.4 \%$, en uno y otro caso. A nivel salarial la desigualdad también resulta significativa, pues se estima que mientras los hombres trabajan 55.4 horas a la semana y reciben 18.2 pesos por hora, la mujer labora 66.3 horas y obtiene sólo 16.7 pesos, lo que representa una diferencia de 10.9 horas y 1.5 pesos, respectivamente. A pesar de lo anterior, el reto en esta materia persiste en las actividades domésticas, pues en $93.6 \%$ de los casos, son mujeres

10 Véase Reporte Global de Brecha de Género 2008 (The Global Gender Gap Report 2008), Foro Económico Mundial, Ginebra, 2008, disponible en http://www.weforum.org/ pdf/gendergap/report2008.pdf, última visita: 23 de mayo de 2009). El reporte proporciona puntos de referencia nacionales que miden la brecha de género en lo económico, político, educativo y salud y, en función de ellos, clasifica a los países. Esto permite elaborar comparaciones por regiones, niveles de ingreso y tiempo, p. 11.

11 Véase Encuesta Nacional de Ocupación y Empleo 2008 publicada por el Instituto Nacional de Estadística, Geografía e Informática (INEGI).

12 Idem. 
quienes las realizan, lo que no ayuda a desvirtuar el estereotipo de papel "privado y reproductivo" que por muchos años caracterizó a la mujer mexicana.

Por lo que se refiere al aspecto educativo, si bien subsisten desigualdades entre ambos sexos, se ha producido un crecimiento progresivo en el acceso educativo de las mujeres: el analfabetismo femenino disminuyó $5.3 \%$ en contraposición con el masculino que, en el mismo periodo, decreció sólo $2.8 \%$. No obstante, algunas diferencias aún continúan, pues la proporción de hombres que asiste en edad escolar a los planteles educativos es de 58.5 contra $55.6 \%$ de las mujeres.

En materia de salud también se han registrado avances importantes; actualmente, la esperanza de vida de las mujeres es de 77.2 años contra los 71.8 años de los hombres ${ }^{13}$ y se ha disminuido el número de defunciones por mortalidad materna; ${ }^{14}$ sin embargo, aún se observa un alto porcentaje de fallecimientos por cáncer de mama (13.8\%) y cérvico-uterino (12.1\%). El gran reto ahora es el sobrepeso y la obesidad, pues el 71.9\% de la población femenina la padece contra el $66.7 \%$ de la masculina.

A pesar de los compromisos asumidos por México en el ámbito internacional, ${ }^{15}$ la representación política de la mujer aún vive una situación de rezago. De los 128 escaños que componen el Senado de la República, 23 los ocupa el sexo femenino, lo que apenas representa el 17.96\%, mientras que 105 senadores hombres, lo cual significa el $82.03 \%$ en dicha Cámara. En la Cámara de Diputados la situación es muy similar, pues de los 500 legisladores, únicamente 138 son mujeres y 362 hombres, o sea 27.6 frente a $72.4 \%$. Por lo que respecta a la intervención de la mujer en el proceso de toma de decisiones, su participación todavía es menor, pues de los 52 cargos de primer mando que existen en el gobierno federal y de las 32 gubernaturas de las entidades federativas, sólo 9 y 2, respectivamente, son ocupados por mujeres, ${ }^{16}$ esto sin contar que únicamente presiden 111 de los 2,440 municipios que integran el territorio nacional. Fi-

13 Véase Informe Especial sobre el Derecho de Igualdad entre Hombres y Mujeres, México, Comisión Nacional de los Derechos Humanos, 2007, p. 51.

14 En el 2007 se produjeron 1,136 defunciones por mortalidad materna, lo que implica que tres mujeres fallecieron diariamente debido a complicaciones en el embarazo, parto o puerperio. Véase Informe Especial, supra, nota 13, p. 57.

15 Dichos acuerdos comenzaron a partir de la Plataforma de Acción de Beijing, luego de la IV Conferencia Mundial Sobre la Mujer realizada en esa ciudad en 1985.

16 En México existen 32 entidades federativas: 31 estados y un Distrito Federal. 
nalmente, conviene decir que a diferencia de algunos países de la región como Argentina, Chile, Panamá o Nicaragua, en México ninguna mujer ha ganado una elección para ocupar la Presidencia de la República.

Al comenzar esta década, México inició una intensa actividad legislativa que ha creado mecanismos, programas e instituciones orientados a disminuir la brecha de desigualdad entre hombres y mujeres. Así, se han adoptado importantes instrumentos como la Ley General para la Igualdad entre Mujeres y Hombres ${ }^{17}$ y la Ley General de Acceso a las Mujeres a una Vida Libre de Violencia, ${ }^{18}$ esta última enfocada a atender un problema muy grave en nuestro país: la violencia de género. El Instituto Nacional de las Mujeres representa uno de los resultados más tangibles de dicha actividad legislativa, pues se trata del órgano encargado de dirigir la política nacional para lograr la igualdad de oportunidades entre mujeres y hombres, a través de la institucionalización y transversalización de la perspectiva de género en las acciones del Estado mexicano. ${ }^{19} \mathrm{~A}$ la Comisión Nacional de los Derechos Humanos le corresponde, específicamente, observar el seguimiento, evaluación y monitoreo de esa política nacional. Para ella, desde 2006, creó el Programa de Igualdad entre Hombres y Mujeres que, de entre sus muchos objetivos, se encuentran los de atender quejas en materia de igualdad; plantear propuestas de conciliación y, de ser el caso, emitir recomendaciones e informes especiales. El propósito del programa es, finalmente, contribuir a la eliminación de los estereotipos y la modificación de los roles de género culturalmente prestablecidos, para alcanzar así la tan anhelada igualdad sustantiva entre mexicanos y mexicanas.

\section{HOMOFOBIA Y DERECHOS HUMANOS}

Estrechamente vinculado con el tema de la igualdad, se encuentra el de la tolerancia. Originada como una estrategia del absolutismo para poner fin a las guerras de religión y solucionar el problema de las guerras civiles motivadas por diferencias religiosas. ${ }^{20}$ La tolerancia significa res-

17 Diario Oficial de la Federación del 2 de agosto de 2006.

18 Diario Oficial de la Federación del 1o. de febrero de 2007.

19 Para conocer más de dicho Instituto, visite $w w w$.inmujeres.gob. $m x$

20 Gutiérrez, Carlos, "Tolerancia, despropósito conceptual en nuestros días", en Villar Borda, Luis y Rosales, José María (eds.), Las razones de la convivencia, Bogotá, Universidad Externado de Colombia, 2007, pp. 85-99. 
petar la conducta u opinión de los demás cuando resulte contraria a la nuestra. Conceptualmente, su definición no entraña mayor problema: sin embargo, la realidad del siglo XXI le plantea retos importantes a un concepto surgido en el siglo XVI. Me gustaría referirme a uno de ellos: la homofobia.

El término homofobia refiere a un prejuicio que atribuye características negativas a las personas por el hecho de ser homosexuales o de tener conductas de afecto o deseo erótico con personas de su mismo sexo, o bien, relacionadas con la homosexualidad, por ejemplo, hacia personas que parezcan serlo de acuerdo con los estereotipos social y culturalmente definidos.

La homofobia se vuelve así un condicionante para una serie de situaciones que comprometen la convivencia civilizada, la atención de problemas de salud que atañen a las personas que tienen prácticas sexuales con personas de su mismo sexo y motivan acciones represivas, intolerantes, discriminatorias o francamente negativas. La homofobia es, pues, un fenómeno sociocultural que da lugar a hechos que pueden ser violatorios de los derechos humanos. En sí mismo, es un problema más social que individual; más cultural que de hechos particulares. Se parece al machismo, ese prejuicio sexista, que ideológicamente condiciona la aparición de problemas, desde la inequidad hasta la violencia contra las mujeres; en este caso, de la misma manera, las prácticas homofóbicas van desde la ridiculización hasta la violencia homicida.

La homofobia todavía es un problema alarmante en México. En 2001, una encuesta a nivel nacional reveló que el $66 \%$ de los entrevistados no compartiría el techo con un homosexual. ${ }^{21}$ En 2005, otra encuesta dio a conocer que para el $94.7 \%$ de los homosexuales, existe discriminación en su contra. El 42.8\% declaró haber sido víctima de actos discriminatorios en el último año y el $40.1 \%$ padeció los mismos actos pero en su centro de trabajo. El 60\% ubicó como su principal enemigo a la sociedad misma; el 70\% reconoció que la discriminación en su contra había aumentado en los últimos cinco años; dos de cada tres sintieron que no les

21 Véase Primera Encuesta Nacional sobre Cultura Política y Prácticas Ciudadanas, elaborada por la Secretaría de Gobernación (Segob) y el Instituto Nacional de Estadística, Geografía e Informática (INEGI) en 2001, disponible en: http://encup.gob.mx/encup/ index.php? page=primera-encup-bd, última visita: 3 de julio de 2009 . 
fueron respetados sus derechos y más de la mitad confesó sentirse rechazado por la sociedad. ${ }^{22}$

En cuanto al rubro de la violencia, una organización de la sociedad civil $^{23}$ documentó en su último reporte (2007) un promedio de tres homicidios mensuales a personas de la comunidad lésbico, gay, bisexual y transgénero en el país. Afirmó que de los 464 crímenes de odio por homofobia en el periodo 1995-2007, 445 fueron cometidos contra personas del sexo masculino y 18 del femenino, con 52 trasvestis o transgénero. ${ }^{24} \mathrm{El}$ $98 \%$ de los casos siguen impunes. Quienes realizan este seguimiento estadístico suelen afirmar que los agentes del Ministerio Público no llevan adecuadamente las investigaciones de tales homicidios, pues argumentan que se trata de "crímenes pasionales", hipótesis que utilizan como justificación para no entrar al estudio de otros móviles.

La CNDH ha emitido dos recomendaciones relacionadas con la homofobia homicida. En la primera constató la deficiente actuación de las autoridades en la investigación de homicidios en contra de personas que se presume - de acuerdo con lo manifestado por la sociedad civil— eran de orientación diferente a la heterosexual. ${ }^{25}$ En la segunda, subrayó las omisiones del Ministerio Público al integrar un expediente, abierto por motivo del delito de homicidio cometido en contra del presidente de una organización civil ${ }^{26}$ y que fue encontrado amordazado y asesinado en su departamento en la ciudad de México. En este caso, la CNDH recomendó además el perfeccionamiento y determinación legal de las indagatorias, así como el inicio del procedimiento administrativo en contra de los ser-

22 Véase Primera Encuesta Nacional sobre Discriminación en México, elaborada por la Secretaría de Desarrollo Social (Sedesol) y el Consejo Nacional para Prevenir la Discriminación (Conapred) en 2005, disponible en: http://sedesol2006.sedesol.gob. $\mathrm{mx} /$ subsecretarias/prospectiva/discriminación/Resumen/Presentacion\%20de\%20la\%20 Encuesta.pdf, última visita: 3 de julio de 2009.

23 Comisión Ciudadana Contra los Crímenes de Odio por Homofobia.

24 Véase "Odio a muerte", reportaje publicado en el periódico La Jornada el 4 de junio de 2009.

25 Véase Recomendación 113/93 del 20 de julio de 1993.

26 Se trata de Ave México, organización cuyos esfuerzos se han enfocado a la capacitación y prevención de enfermedades de la salud sexual como el VIH-SIDA. Más información en www.avedemexico.org.mx, última visita: 3 de julio de 2009. 
vidores públicos debido a la dilación observada en la integración de las indagatorias. ${ }^{27}$

México necesita sumar esfuerzos para cambiar los ambientes de tolerancia, rechazo o desprecio en su sociedad y abatir así los crímenes de odio, que representan la manifestación más brutal de la homofobia. Dicha fobia también ha dificultado atender un problema de salud de primordial importancia: el VIH entre la población de hombres que tienen sexo con otros hombres, sea que se asumen como homosexuales o no. Un contexto homófobo aleja a las personas de la prevención, de la detección oportuna $y$, en consecuencia, de mayores opciones de tratamiento. La homofobia afecta las estrategias de prevención del VIH debido al temor de ser expuesto como homosexual en caso de que alguien decida realizarse una prueba de diagnóstico; también dificulta la atención de la enfermedad, pues ahuyenta a los usuarios de los centros y servicios de salud. El mayor daño se presenta, no obstante, cuando estas prácticas se institucionalizan, pues violan reiteradamente la dignidad de las personas pertenecientes a este grupo vulnerable, al negárseles el pleno ejercicio de sus derechos a la igualdad, a la no discriminación y a la protección de la salud.

La Comisión Nacional de los Derechos Humanos ha reconocido al VIH-SIDA no sólo como un problema en materia de políticas públicas, sino también de derechos humanos, pues los portadores de esa enfermedad conforman un grupo de extrema vulnerabilidad y muy poca visibilidad social en la sociedad mexicana. Las condiciones de salud no deben ser motivo de estigma. Por ello, en 2004 creó el Programa VIH-SIDA, un programa institucional cuyo objetivo último es contribuir a la consolidación de la cultura de respeto a los derechos fundamentales, ya sea de quienes han dado positivo a la presencia de ese mal, o bien, de los que ya viven con él. Entre sus facultades se encuentran las de atender y trabajar tanto con organizaciones de la sociedad civil como con organismos públicos encargados de la materia, elaborar campañas de difusión de los derechos humanos de las personas que viven con VIH-SIDA, capacitar a servidores públicos y desarrollar programas educativos de prevención. ${ }^{28}$

27 Véase Recomendación 102/94 del 31 de agosto de 1994.

28 Para conocer más acerca de este programa consulte http://www.cndh.org.mx/progate/vihsida/presentación.htm. 


\section{PUEBLOS INDÍGENAS}

Finalmente, al hablar de igualdad, discriminación y tolerancia en México, no puedo dejar de mencionar algunas ideas relacionadas con la cuestión indígena. La nación mexicana - dice nuestra Constitución-es única e indivisible y tiene una composición pluricultural sustentada originalmente en sus pueblos indígenas, que son aquellos que descienden de poblaciones que habitaban en el territorio actual del país al iniciarse la colonización y que conservan sus propias instituciones sociales, económicas, culturales y políticas, o parte de ellas. ${ }^{29}$ Esta disposición fue incorporada en 2001, luego de una reforma constitucional que reivindicó los derechos de este grupo vulnerable. A pesar de dicha reforma, los problemas de discriminación aún persisten.

De acuerdo con la encuesta nacional a la que me referí anteriormente, nueve de cada diez indígenas opinó que en México se les discrimina por su condición. El 90.3\% consideró que tiene menos oportunidades para conseguir empleo; tres de cada cuatro estimaron lo mismo pero en relación con el acceso a la educación; 45\% afirmó que no le fueron respetados sus derechos por el hecho de ser indígena, mientras que uno de cada tres fue discriminado en el año anterior y a uno de cada cinco le negaron el trabajo por ese mismo motivo. Finalmente, dos de cada tres miembros de este grupo vulnerable manifestó tener pocas o nulas posibilidades para mejorar sus condiciones de vida. ${ }^{30}$

Como respuesta a la situación de especial vulnerabilidad en la que se desarrolla la vida de millones de indígenas, la Comisión Nacional de los Derechos Humanos creó, en 1994, la Cuarta Visitaduría General como un área especializada en la protección, defensa, promoción y difusión de los derechos humanos de los pueblos indígenas en México. Esta oficina atiende quejas y promueve el respeto de dichos derechos, tanto en su dimensión individual como colectiva, con especial atención en la preservación de los elementos que componen sus culturas e identidades. Lo anterior conforme a lo establecido por la propia carta magna y los instrumentos internacionales firmados y ratificados por el Estado mexicano. ${ }^{31}$

29 Artículo 2o. de la Constitución Política de los Estados Unidos Mexicanos.

30 Primera Encuesta Nacional sobre Discriminación en México, op. cit., nota 22.

31 Por ejemplo, el Convenio 169 sobre Pueblos Indígenas y Tribales en Países Independientes de la Organización Internacional del Trabajo. 
Una de las áreas en las que ha trabajado más intensamente la Comisión Nacional es en la atención de la población indígena en reclusión. En este caso en particular, la referida Visitaduría lleva a cabo acciones relativas a la obtención de las "libertades anticipadas" de los indígenas presos, tanto en el ámbito federal como en el local. En 2009, la CNDH presentó 1,162 propuestas de "libertades anticipadas", 295 a la autoridad federal y 867 a la local. El resultado fue 958 indígenas liberados, lo cual representa una cifra importante.

\section{EXPECTATIVAS}

Aún falta mucho por hacer en materia de igualdad, discriminación y tolerancia en México. Cierto es que los retos se antojan desafiantes, pero, lo cierto también es, que las posibilidades de solución son numerosas. La experiencia internacional representa sin duda una gran ayuda, pues proporciona los avances y retrocesos que otras naciones han alcanzado en lo que, finalmente, es el anhelo común de las sociedades modernas: la consolidación del régimen democrático de derechos humanos. 